\title{
The Impact of Variable Thermal Conductivity of Insulation Materials on the Building Energy Performance in Hot Climate
}

\author{
Maatouk Khoukhi*, Ahmed Hassan, and Shaimaa Abdelbaqi \\ College of Engineering, United Arab Emirates University, PO Box 15551, Al Ain, UAE
}

\begin{abstract}
This paper illustrates the impact of embedding an insulation layer of variable thermal conductivity in a typical building wall on the cooling effect and energy performance. The evaluation was performed by applying a conjugate heat transfer model, which was tested in extremely hot conditions of Al Ain (UAE). The thermal performance of a building incorporating insulation layers of variable thermal conductivity (k-value) was compared to a non-variable thermal conductivity system by quantifying the additional heat transferred due to the k-relationship with time. The results show that, when the k-value is a function of operating temperature, its effects on the temperature profile through the wall assembly during daytime is significant compared with that obtained when a constant k-value for the polystyrene (EPS) insulation is adopted. A similar trend in the evolution of temperatures during the day and across the wall section was observed when EPS material with different moisture content was evaluated. For the polyurethane insulation, the inner surface temperature reached $44{ }^{\circ} \mathrm{C}$ when constant $\mathrm{k}$-value was adopted, increasing to $48.5{ }^{\circ} \mathrm{C}$ when the $\mathrm{k}$-value was allowed to vary under the same ambient conditions.
\end{abstract}

\section{Introduction}

The U.S. Energy Information Administration's latest International Energy Outlook 2017 (IEO2017) projects that world energy consumption will grow by $28 \%$ between 2015 and 2040. Most of this growth is expected to come from countries that are not in the Organization for Economic Cooperation and Development (OECD), and especially in countries where demand is driven by strong economic growth, particularly in Asia [1].

In harsh climatic with less industrial activities, the AC system represent the main source of energy consumption and may reach $70 \%$ of the total energy consumption [2]. Regulations have been then set in many countries worldwide to assess the energy consumed in buildings. Several energy saving standards have also been adopted in European countries following the 1973 energy crisis. The most effective way for reducing the building energy consumption is the use of low thermal conductivity of the building envelope layers particularly the insulation with low thermal conductivity below $0.1 \mathrm{~W} / \mathrm{mK}$. Indeed, in Europe, energy savings in buildings are enforced by several recent policies, such as the Energy Performance of Building Directive (EPBD) [3] and the Energy Efficiency Directive (EDD) [4].

When assessing building energy performance, the overall heat transfer coefficient (U-value) of the envelope which is mainly function of the thermal conductivity of the different layers is assumed to be constant and do not change with the change of temperature and humidity for instance. Actually, this is not true and several researchers have reported that the thermal conductivity of different insulation materials is a function of operating temperature and mo isture content.
Most of the authors of pertinent studies have found that the k-value of most insulating materials rises as the influencing temperature increases [2, 5]. Aldrich and Bond investigated the effects of temperature on the thermal performance of rigid cellular foam [6]. Their results show a significant change in the k-value as a result of temperature changes. Khoukhi and Tahat also investigated variations in the k-values as a function of density, operating temperature, and humidity content of EPS insulation material, and the effects of these changes on the cooling load required by buildings [7, 8].

Several authors also investigated the impact of moisture content on the thermal conductivity of insulation materials. In these studies, thermal performance of polyurethane insulation [9], fiberglass [10] and mineral wool [11] expended for cooling and heating pipes exposed to the underground water attacks was investigated. The reported results indicate that thermal conductivity was $35-50 \%$ higher than the value obtained when the differences in temperature were larger. Similarly, Liu et al. reported that the accumulation of mo isture and its transfer through exterior walls have a significant impact on the cooling and heating transmission [12].

Although extensive work has been conducted on the combined effect of operating temperature and moisture content variations and their impact on the change in the $\mathrm{k}$-value of several building insulation materials, the impact of these changes on the heat transfer through the building envelope remains insufficiently explored.

Given the aforementioned observations, the main objective of the present study was to investigate the effects of temperature and moisture content variations on the heat transfer through the wall assembly. The heat 
transfer amount variations were quantitatively assessed for various building insulation material types during daytime and over the entire 24-hour period in summer months. The difference in heat transfer based on constant and variable insulation thermal conductivity (henceforth denoted as constant-k and variable-k cases) was calculated and the ambient cooling requirements were assessed accordingly.

\section{Numerical model}

A typical one-story building $\left(20 \times 20 \times 3 \mathrm{~m}^{3}\right)$ located in Al Ain (UAE), with a commonly used wall construction assembly comprising of $200 \mathrm{~mm}$ thick concrete block layer, a $50 \mathrm{~mm}$ insulation layer, a $13 \mathrm{~mm}$ thick interior gypsum board, and a $19 \mathrm{~mm}$ concrete stucco at the exterior surface was numerically studied.

A two-dimensional, finite-volume heat transfer model of the building wall was developed, as illustrated in Fig. 1, to simulate the thermal impact of applying different insulation materials with constant and variableK.

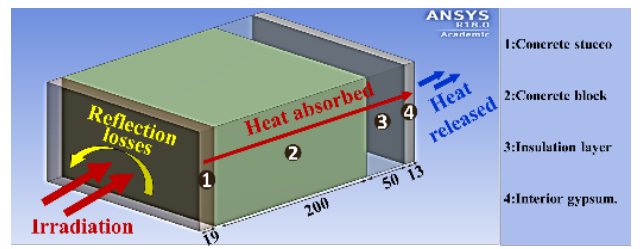

Fig. 1. Schematics of the energy flow in the wall cross-section

Thermal boundary conditions were applied, with the exterior concrete stucco treated as the system input heat flux boundary, including incident irradiance $(q)$.

The two-dimensional differential equation given below governs the transient heat transfer [13]:

$$
\rho c \frac{\partial T}{\partial t}-\left[\frac{\partial}{\partial x_{i}}\left(k_{i j} \frac{\partial T}{\partial x_{j}}\right)\right]+Z_{c}+Z_{r}=0
$$

where $\rho$ : density, $C$ : heat capacity, $\kappa$ : thermal conductivity of the material, $T$ : temperature, $t$ : time, and $x_{i}$ and $x_{j}$ : unit vectors. The heat convection and radiation losses $\left(Z_{c}\right.$ and $Z_{r}$ ) in Eq. (1) are calculated using the expressions [14]:

$$
\begin{aligned}
& Z_{c}=h_{c} A\left(T-T_{a m b}\right) \\
& Z_{r}=\sigma \varepsilon A\left(T^{4}-T_{\infty}{ }^{4}\right)
\end{aligned}
$$

where $h_{c}$ is the convective heat loss coefficient, $A$ is the stucco wall surface area (0.92), $\sigma$ denotes StefanBoltzman constant, $T_{a m b}$ is ambient temperature, and $T_{\infty}$ represents the outdoor air temperature. The convective heat loss coefficients $\left(h_{c}\right)$ is calculated by applying the Nusselt number $(\mathrm{Nu})$ given by Eq. (4) [14]:

$$
h_{c}=K L N u
$$

where $K, L$ and $N u$ : air conductivity, characteristic length, and Nusselt number, respectively. The Nusselt number is calculated based on the fundamental air properties, through the Prandtl number ( $P r)$ relationship (Eq. (5)) and the Reynolds number $(\operatorname{Re} L)$ relationship (Eq. (6)) [14]:

$$
\begin{aligned}
& P r=v \frac{C p}{K} \\
& R e L=V L v
\end{aligned}
$$

where $v$ and $V$ are viscosity and air velocity, respectively.

The density, the velocity vector, and the specific heat capacity for the materials (denoted by $\rho, u_{j}, c_{p}$, respectively) are assumed to be independent of temperature, while the thermal conductivity $(k)$ of the insulation material is treated as a function of temperature, and is defined by Eq. (7) [13]:

$$
k(T)=C_{1}+C_{2} T+C_{2} T^{3} \ldots \ldots
$$

where $C$ is constant.

The problem was modeled and solved in ANSYS platform (Version 18, Cecil Township, PA, USA, 2015), adopting Al Ain climatic conditions, characterized by very hot weather in July. The solution is updated at 1minute intervals, i.e., a fter co mp leting 20 ite rations, for a total run time of 24 hours. Thermo-physical properties of

\begin{tabular}{|c|c|c|}
\hline Material & Density $\left(\mathrm{kgm}^{-3}\right)$ & Thermal conductivity $\left(\mathrm{Wm}^{-1} \mathrm{~K}^{-1}\right)$ \\
\hline Concrete stucco & 2000 & 1.2 \\
\hline Concrete block & 664 & 0.14 \\
\hline Interior gypsum & 625 & 0.16 \\
\hline \multirow{4}{*}{ Polystyrene } & 12 & $\mathrm{k}_{\mathrm{LD}}(\mathrm{t})=9 \times 10^{-5}(\mathrm{~T})+0.0372\lceil 2\rceil$ \\
\hline & 20 & $\mathrm{k}_{\mathrm{HD}}(\mathrm{t})=6 \times 10^{-3}(\mathrm{~T})+0.0357[2]$ \\
\hline & 30 & $\mathrm{k}_{\mathrm{UHD}}(\mathrm{t})=5 \times 10^{-5}(\mathrm{~T})+0.0347[2]$ \\
\hline & 35 & $\mathrm{k}_{\mathrm{SHD}}(\mathrm{t})=6 \times 10^{-5}(\mathrm{~T})+0.033[2]$ \\
\hline \multirow{2}{*}{ Fiberglass } & 13.1 & $\mathrm{k}_{\mathrm{FG}-\mathrm{LD}}(\mathrm{t})=3.36810^{-4}(\mathrm{~T})+0.041433[15]$ \\
\hline & 27 & $\mathrm{k}_{\mathrm{FG}-\mathrm{MD}}(\mathrm{t})=1.77510^{-4}(\mathrm{~T})+0.032404[15\rceil$ \\
\hline \multirow{3}{*}{ Rockwool } & $\frac{30}{50}$ & $\left.\mathrm{k}_{\mathrm{EG}-\mathrm{HD}} \mathrm{t}\right)=1.18910^{-4}(\mathrm{~T})+0.029130[15$ \\
\hline & 75.5 & $\begin{array}{ll}\mathrm{K} R W-\mathrm{LD} \\
\mathrm{K}_{\mathrm{P} W-}(\mathrm{t})=1.68310^{-4}(\mathrm{~T})+0.030341\end{array}$ \\
\hline & 125.7 & $\mathrm{k}_{\mathrm{RW-HD}}(\mathrm{t})=1.78910^{-4}(\mathrm{~T})+0.036261[15]$ \\
\hline Polyethylene & 26 & $\mathrm{k}_{\text {polyethy }}(\mathrm{t})=3.83710^{-4}(\mathrm{~T})+0.052988[15]$ \\
\hline Polyurethane & 44 & $\mathrm{k}_{\text {polyuret }}(\mathrm{t})=1.08910^{-4}(\mathrm{~T})+0.020132[15]$ \\
\hline
\end{tabular}
materials comprising the modelled wall layer are given in Table 1 and Thermo-physical properties of LD insulation at different moisture content are given in Table 2.

Table 1. Thermo-physical properties of materials comprising the modelled wall layer.

Table 2. Thermo-physical properties of LD insulation at different moisture content [2].

\begin{tabular}{|l|c|c|c|}
\hline Material & Density $\left(\mathrm{kgm}^{-3}\right)$ & Moisture (\%) & Thermal conductivity $\left(\mathbf{W m}^{-1} \mathbf{K}^{-1}\right)$ \\
\hline \multirow{2}{*}{ Polystyren } & \multirow{2}{*}{12} & 10 & $\mathrm{k}(\mathrm{t})=9 \times 10^{-5}(\mathrm{~T})+0.0386$ \\
& & 20 & $\mathrm{k}(\mathrm{t})=9 \times 10^{-9}(\mathrm{~T})+0.0403$ \\
& & 30 & $\mathrm{k}(\mathrm{t})=8 \times 10^{-3}(\mathrm{~T})+0.0426$ \\
\cline { 2 - 3 } & & &
\end{tabular}

\section{Results and discussion}

The solar radiation, ambient temperature, and wind velocity specific to the Al A in (UAE) climatic conditions served as inputs to the numerical model, the aim of which was to assess the effect of variable thermal conductivity on the heat transferred from the outer surface of the building to the indoor space and compare the findings to those pertaining to the reference case based on constant thermal conductivity. The surface temperature was monitored at different locations across the wall (Fig. 2.)

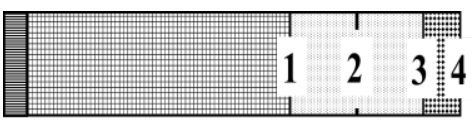

Fig. 2. Schematic diagram of a wall section, whereby 1 is located between the concrete block and insulation layers, 2 is the middle of insulation layer, 3 located between the insulation and gypsum board layers, and 4 is the inner surface.

\subsection{Density effect}

The temperature profiles at the concrete-insulation boundary, middle of the insulation, insulation-gypsum boundary, and the inner surface (representing four distinct EPS density levels) are shown in Fig. 3. It can be noted that, during daytime, adopting variable $\mathrm{k}$-value 
results in a greater temperature increase on the surfaces compared to the reference case based on constant thermal conductivity of the insulation material. This discrepancy is due to the increased heat transfer owing to the higher thermal conductivity resulting from variable $\mathrm{k}$. In the morning, the temperature obtained when using a constant $\mathrm{k}$ (solid lines) is similar to that when variable $\mathrm{k}$ (dashed lines) is adopted, but this difference gradually increases as the ambient temperature and solar radiation increase during daytime. However, the trend is reversed at nighttime, whereby the model based on variable $\mathrm{k}$ produces lower surface temperatures compared to those obtained in the reference case. However, in the subsequent wall layers, differences start to emerge. As the heat is transferred to the interior layers, the temperature difference between the two cases (based on variable and constant $\mathrm{k}$ ) increases, reaching maximum on the surfaces located after the insulation layer toward the inner surface.

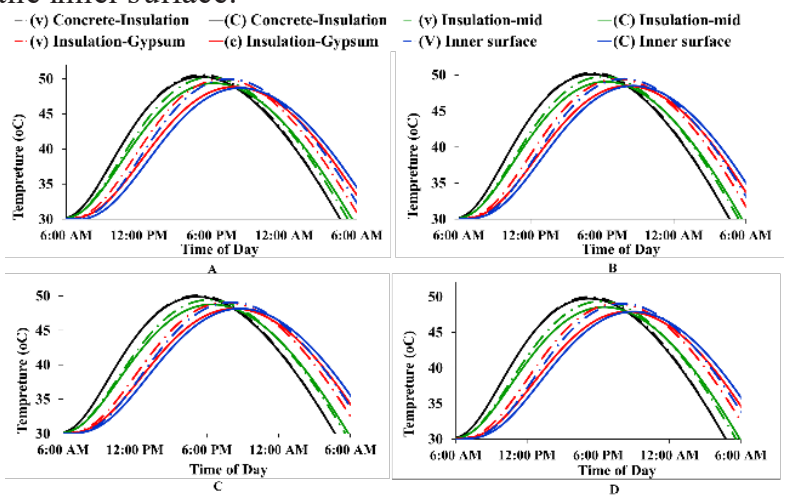

Fig. 3. Temperature profile at different positions for constant-K as a reference (solid lines) and variable-K (dashed lines) for polystyrene (A) LD, (B) HD, (C) UHD, and (D) SHD.

\subsection{Moisture effect}

A similar trend in the evolution of temperatures during the day and across the wall section is observed in Fig. 4, when the effects of moisture content were assessed for the low-density EPS insulation. The difference decreases slightly as the moisture content increases. At nighttime, when the ambient temperature decreases, the heat transferred to the interior wall surfaces decreases, resulting in a higher inner surface temperature compared to the concrete-insulation contact surface, irrespective of whether variable or constant $\mathrm{k}$ is used.

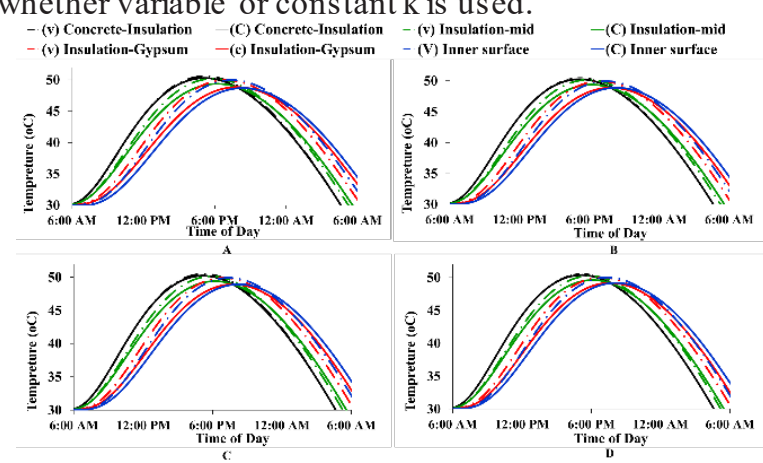

Fig. 4. Temperature profile at different positions for constant-K as a reference (solid lines) and variable-K (dashed lines) for LD polystyrene with (A) $0 \%$, (B) $10 \%$, (C) $20 \%$, and (D) $30 \%$ moisture content.

\subsection{Different insulation materials}

The study was further extended to evaluate the impact of $\mathrm{k}$-value change on the temperature increase within a typical wall of a residential building incorporating different insulation materials. Fig. 5 shows the evolution of temperature at different locations across a wall section based on variable and constant $\mathrm{k}$ values pertaining to fiberglass with the density of $13.1 \mathrm{~kg} / \mathrm{m}^{3}$ (Fig. 5-A), 27 $\mathrm{kg} / \mathrm{m}^{3}$ (Fig. 5-B), and $56 \mathrm{~kg} / \mathrm{m}^{3}$ (Fig. 5-C); as well as rock wool with the density of $50 \mathrm{~kg} / \mathrm{m}^{3}$ (Fig. 5-D), 75.5 $\mathrm{kg} / \mathrm{m}^{3}$ (Fig. 5-E) and $125.7 \mathrm{~kg} / \mathrm{m}^{3}$ (Fig. 5-F); and finally polyethylene with the density of $26 \mathrm{~kg} / \mathrm{m}^{3}$ (Fig. 5-G) and polyurethane with the density of $44 \mathrm{~kg} / \mathrm{m}^{3}$ (Fig. 5-H).

Values obtained when applying the variable $\mathrm{k}$ on the inner surface in the case of fiberglass with low density (Fig. 5-A), moderate density (Fig. 5-B) and high density (Fig. 5-C) indicate that better performance is ach ieved at lower densities, as indicated by the lowest temperature differential between the results based on variable and constant $\mathrm{k}$. However, during nighttime, this trend is reversed, as the insulation layer retains the least amount of heat to transmit towards the building interior. Fig. 5-D, 5-E and 5-F, pertaining to the case based on the rock wool as an insulation material with different levels of density (LD, MD and HD), respectively, show that moderate-density rock wool results in the lowest difference between the variable-k and constant-k cases. The polyethylene insulation (Fig. 5-G) results in the lowest difference between the variable-k and the constant-k cases. Conversely, inclusion of polyurethane (Fig. 5-H) as an insulation material results in the greatest difference between the two cases.
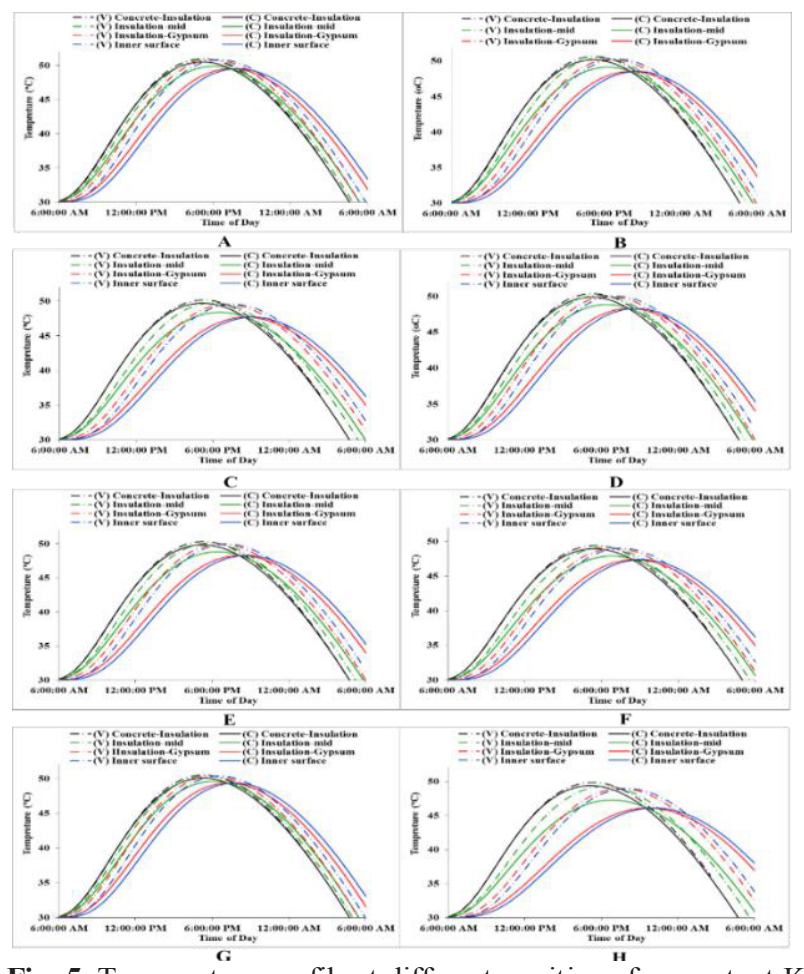

Fig. 5. Temperature profile at different positions for constant-K as a reference (solid lines) and variable-K (dashed lines) of (A) fiberglass - LD, (B) fiberglass - MD, (C) fiberglass - HD, (D) rock wool - LD, (E) rock wool - MD, (F) rock wool - HD, (G) polyethylene, and $(\mathbf{H})$ polyurethane. 
The additional temperature rise on the inner wall surface due to applying variable $\mathrm{k}$ compared to the known constant $\mathrm{k}$ of a particular insulation material was calculated for each of the insulation materials examined in the present study. Findings pertaining to different polystyrene density levels revealed that the inner surface temperature obtained when variable $\mathrm{k}$ was used decreased as the density level increased. The highest temperature rise on the inner surface due to apply ing variable $\mathrm{k}$ of polystyrene occurs when low-density polystyrene is employed, reaching the maximum and average daily difference of $2.3^{\circ} \mathrm{C}$ and $1.25^{\circ} \mathrm{C}$, respectively. Conversely, for polystyrene with UHD, $1.7^{\circ} \mathrm{C}$ and slightly less than $1^{\circ} \mathrm{C}$ higher temperatures are obtained with variable compared to the reference $\mathrm{k}$, as a maximum and average daily difference, respectively (see Fig. 6).

When LD polystyrene with different moisture levels was examined, the findings revealed that the inner surface temperature decreases as the moisture content increases. When dry LD polystyrene (with $0 \%$ moisture content) was incorporated in the building wall, model based on variable $\mathrm{k}$ produced a maximum temperature increase of about $2.2^{\circ} \mathrm{C}$ on the inner wall surface and around $1.2^{\circ} \mathrm{C}$ average daily increase relative to the constant-k case. As can be seen in Fig. 6, the optimum mo isture content is $30 \%$, as it yields the lowest inner surface temperature difference $\left(0.9^{\circ} \mathrm{C}\right.$ on average $)$ between the variable-k and constant-k cases. This reduction in the discrepancy between the two cases as the mo isture content increases can be attributed to the lower heat transfer due to higher porosity because of water evaporation at higher temperatures.

Evaluation of different insulation material types shows that, as the fiberglass density increases, the difference between the variable-k and the constant-k case decreases. However, the decrement in the temperature difference among insulations with different densities is not significant, as shown in Fig. 6. The maximum temperature differential is $3.3^{\circ} \mathrm{C}, 3.5^{\circ} \mathrm{C}$ and $3.6^{\circ} \mathrm{C}$ for lower, moderate and higher density, respectively, averaging at around $1.6^{\circ} \mathrm{C}$. The low- and high-density rock wool insulation material produced almost the same values as fiberglass-MD. However, the temperature difference between the variable-k and constant-k cases when moderate-density rock wool insulation was considered was the smallest among all studied insulation materials, with the maximum of $0.6^{\circ} \mathrm{C}$. When polyethylene insulation was modeled with variable and constant $\mathrm{k}$, the former produced a $2.8^{\circ} \mathrm{C}$ higher temperature. In case of using polyurethane as an insulation material, almost $4.5^{\circ} \mathrm{C}$ and $2.3^{\circ} \mathrm{C}$ was obtained as the maximum and average daily temperature difference between variable-k and constant-kcases.

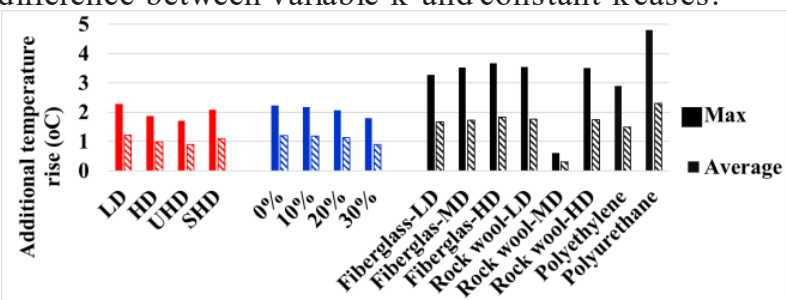

Fig. 6. Temperature difference when calculated based on variable constant-k for different densities (red bars), different moisture levels (blue bars), and different materials (black bars).

\section{Heat transfer analysis}

\subsection{Additional heat release to the building interior}

The additional heat released to the building interior $\left(Q_{a d d}\right)$ by applying the variable-k model of the insulation material relative to the constant-k case as a reference $\left(Q_{\text {ref }}\right)$ is shown in Fig. 7. The $Q_{a d d}$ is obtained by subtracting the $Q_{\text {ref }}$ from $Q_{\text {variable }}$, as shown in Eq. (8).

$$
Q_{\text {add }}=Q_{\text {variable }}-Q_{\text {con }}
$$

Fig. 7 shows the difference between the heat released to the building interior in case of polystyrene with different levels of density (Fig. 7-A), different moisture content (Fig. 7-B) and different insulation materials (Fig. 7-C) when variable-k and constant-k models are used. Indeed, the difference between the heats released to the building interior when polystyrene with different density is used is negligible during early morning hours, but this difference increases during the day. The indoor space gains the highest additional amount of heat when lowdensity polystyrene is used, reaching the maximum of 6 $\mathrm{kW}$ around $4 \mathrm{pm}$. In case of UHD, the maximum additional amount of heat released is approximately 1.5 $\mathrm{kW}$, which represents the lowest amount of heat received. The decrement in additional heat released in case of UHD compared to LD can be attributed to more heat being stored in the material due to its high density. For the LD with different moisture content (Fig. 7-B), the highest additional heat is obtained for the dry case, indicating that the additional heat released to the building interior decreases only slightly with the increase in moisture content due to the evaporation process within the insulation layer. Fig. 7-C shows the findings pertaining to the remain ing insulation materials. As can be seen, the lowest additional amount of $1.5 \mathrm{~kW}$ heat is released to the building interior by RW-MD, while polyurethane releases 8 times this amount to the building interior. The HD rock wool releases almost the same amount of heat as HD fiberglass, reaching $8 \mathrm{~kW}$, while the LD fiberglass released up to $8 \mathrm{~kW}$ to the building interior.

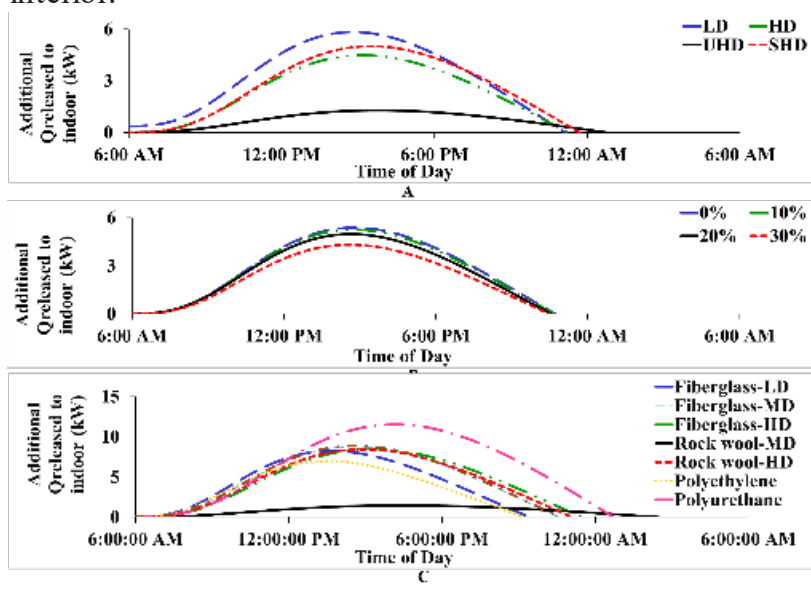

Fig. 7. Additional heat released by applying variable-K of insulation layer for polystyrene with (A) different densities, (B) different moisture content, and (C) different insulation materials over 24-hour period.

\subsection{Net heat added to the building interior}


The increment in the net heat transfer in percentage over a $24 \mathrm{~h}$ (one-day) period, and during daytime, due to applying variable-k model, compared to the reference case based on insulation with constant thermal conductivity, was calculated for different densities of EPS, different moisture content for LD EPS, and different insulation materials (Fig. 8). The percentage of net heat added to the interior was calculating applying Eq. (9).

$$
Q_{\text {net-added }}=\frac{Q_{\text {variable }}-Q_{\text {con }}}{Q_{\text {con }}} * 100
$$

As expected from the previous results, among different polystyrene densities, UHD results in the lowest interior net heat gain of $3 \%$ and $1.5 \%$ during daytime and over the full 24-hour period, respectively. The LD transfers much more heat to the building interior, up to $14 \%$ during daytime and almost 5\% during the full 24-hour period. Thus, additional air conditioning system capacity of $6 \%$ and nearly $3 \%$ is needed when using LD and UHD polystyrene, respectively (see Fig. 9), due to the reduction in heat transfer compared with other densities.

Maximum net heat gain in the building interior when applying variable-k model and considering different mo isture content is achieved for dry polystyrene $(0 \%)$, which transfers up to $13 \%$ more than polystyrene with constant k during daytime, averag ing at 3\% for the entire 24-hour period. As the moisture content increases, the amount of heat transferred decreases due to the absorption-evaporation process within the insulation layers at high temperatures. Polystyrene with 30\% mo is ture content transfers $9 \%$ and $3 \%$ mo re net heat than polystyrene with constant $\mathrm{k}$ during daytime and the full 24-hour period, respectively. The additional air conditioning system capacity required to remove the added heat from the interior space is equal to $5 \%$ in case of dry polystyrene and $3.5 \%$ with $30 \%$ mo isture content (Fig. 9).

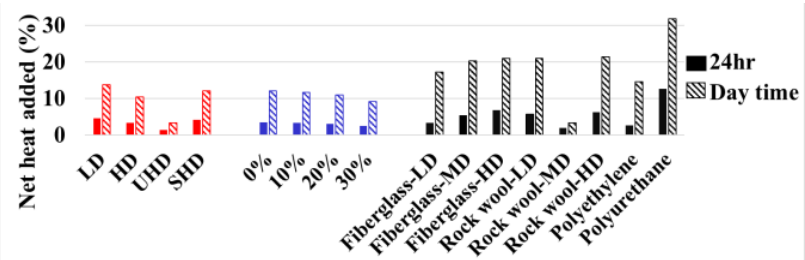

Fig. 8. Net heat added to the building by employing polystyrene insulation with variable-k with different levels of density (red bars) and with different moisture content (blue bars), and different insulation materials (black bars) over a 24hour period and during daytime hours.

The supplemental heat added to the system by applying variable-k build ing envelope model compared to its reference case for different insulation materials was found to reach maximum in case of polyurethane $(32 \%$ and $13 \%$ during daytime and the full 24 -hour period, respectively), thus increasing the air conditioning requirements by $15 \%$ (Fig. 9). Polyurethane was followed by $\mathrm{HD}$ rock wool, HD fiberglass, LD rock wool, MD fiberglass, LD fiberglass, and polyethylene, for which $22 \%$ and $6 \%, 21 \%$ and $7 \%, 20.5 \%$ and $4.9 \%$, $20 \%$ and $4.8 \%, 17 \%$ and $3 \%$ and $14.5 \%$ and $2.5 \%$ increase in heat release was noted during daytime and the full 24-hour period, respectively. The lowest heat added to the building interior when the variable-k was compared to the constant-k was achieved by the MD rock wool, which released only $3 \%$ and $2 \%$ during daytime and over 24-hour period, respectively. MD Rockwool material thus increased the air conditioning systemcapacity by $2.4 \%$ (Fig. 9).

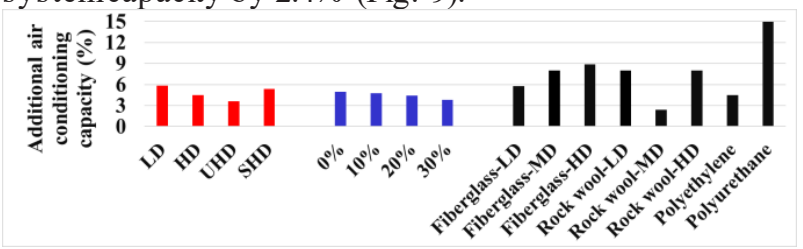

Fig. 9. Additional air conditioning capacity required for building employing polystyrene with variable-k with different levels of density (red bars) and different moisture content (blue bars), and (C) different insulation materials (black bars).

\section{Conclusion}

The present work illustrated the impact of variable thermal conductivity of the insulation layer embedded in typical wall on the cooling effect and energy performance of buildings in extremely hot climate of UAE.

The obtained results show that the LD polystyrene insulation releases the greatest amount of heat to the building interior, reaching up $75.93 \%$ and $72.61 \%$ of the heat gain in variable-k and constant-k cases, respectively and the UHD polystyrene releases the lowest amount of heat to the building interior in both cases among the four levels of the EPS density. The highest heat released to the building interior is obtained for the LD insulation material with $30 \%$ moisture content compared with $10 \%$ and $20 \%$. The LD fiberglass released the maximum amount of heat to the building interior in both variable $-\mathrm{k}$ and constant-k cases, $85.97 \mathrm{kWh}$ and $83.23 \mathrm{kWh}$, respectively. Conversely, rock wool with high density and polyurethane store the highest amount of heat.

The results reported in this paper also indicate that the optimum density level is UHD, as the air conditioning system capacity increases only by about $3.6 \%$. The moisture content was less influential, whereby the maximum air conditioning demand increase of $5 \%$ was noted in case of dry polystyrene, with the minimum of $3.8 \%$ noted for $30 \%$ mo isture content. Different insulation materials were thermally tested, allowing us to conclude that that MD rock wool exhibits the best thermal performance due to releasing the least amount of heat to the building interior $(\leq 3 \%)$, while using polyurethane would lead to an increase of the air conditioning by $15 \%$.

This work is supported by the Research Start-up grant, UAE University (Grant No. G00002665).

\section{References}

1. Today in Energy, September 14, 2017. https://www.eia.gov/todayinenergy/detail.php?id=32 912

2. Khoukhi M. The combined effect of heat and mo is ture transfer dependent thermal conductivity of polystyrene insulation material: impact on building 
energy performance. Energy Build 2018; 228:235169.

3. Energy Performance of Buildings Directive (EPBD), Directive 2010/31/EU of the European Parliament and of the council of 19 May, 2010.

4. Energy Efficiency Directive (EDD), Directive 2012/27/EU of the European Parliament and the council of 25 October, 2012.

5. Khoukhi M, Fezzioui N, Draoui B, Salah L. The impact of changes in thermal conductivity of polystyrene insulation material under different operating temperatures on the heat transfer through the building envelope. Appl Therm Eng 2016; 669:674-105.

6. Aldrich DF, Bond RH. Thermal performance of rigid cellular foam insulation at subfreezing temperature thermal performance of exterior envelopes of buildings III, in: Paper presented at ASHRAE/DOE/BTECC Conference, Florida, USA, 2-5 December, 1985.

7. Khoukhi M, Tahat M. Effect of operating temperatures on thermal conductivity of polystyrene insulation material: impact on envelope-induced cooling load. Appl Mech Mater 2014; 315:320-564.
8. Khoukhi M, Tahat M. Effect of temperature and density variation on thermal conductivity of polystyrene insulation materials in Oman. J Eng Phys Thermophys 2015; 994:998-88.

9. Chyu MC, Zeng X, Ye L. The effect of moisture on the performance of polyurethane insulation used on a district heating and cooling pipe, ASHRAE Trans 1997; 309:317-103.

10. Chyu MC, Zeng X, Ye L. Performance of fibres glass pipe insulation subjected to underground water attack, ASHRAE Trans 1997; 303:308-103.

11. Chyu MC, Zeng X, Ye L. Effect of underground water attack on the performance of mineral wool pipe insulation, ASHRAE Trans 1998; 168:175-104.

12. Liu $X$, Ge $\mathrm{CH}$, Fazio $\mathrm{P}$, Chen $\mathrm{G}$, Guo $X$. Determination of optimum insulation thickness of exterior walls with moisture transfer in hot summer and cold winter zone of China. Energy Build 2015; 361:368-109.

13. Reddy JN, Gartling DK. The Fin ite Element Method in Heat Transfer and Fluid Dynamics. CRC (2001).

14. Cengel, Y. Heat and Mass Transfer: A Practical Approach, 3rd ed.; Mc Graw-Hill: Boston, MA, USA, 2007. 